\title{
The Influence of Impressionist Painting on Xu Beihong's Oil Painting
}

\author{
ZhaoTian Yujun \\ Academy of Fine Arts, Fujian Normal University, Fujian, 350117, China
}

\begin{abstract}
At the beginning of the $20^{\text {th }}$ century, $\mathrm{Xu}$ Beihong studied in France and began his new painting exploration. During the period of staying in France and after returning back to China, Xu Beihong mainly focused on realism painting. However, based on the conclusion of related literature and artworks, it was found that during his stay in France, Xu Beihong not only was engaged in France classical realism oil painting but also was deeply influenced by impressionism. He applied the color and light concept of the impressionism into his own painting, which greatly affected his oil painting creation and his teaching idea after he returned back to China. Through analyzing the study experience, painting language and education philosophy of Xu Beihong, this paper is mainly aimed to elaborate the process and significance of the above-mentioned influence.
\end{abstract}

Keywords: Xu Beihong, Oil Painting, Impressionism, Color, Education

\section{Introduction}

Xu Beihong went to France to accept oversea education on May 10, 1919. He was admitted by National Academy of Fine Arts of Paris to study oil painting, sketch and other western paintings. During the eight-year time (1919-1927) in Europe, he learned from tutors and applied western modeling, composition, color, light, shadow and media in his own works. However, his works in later period did not completely follow the traditional western painting method. Instead, he combined the realism and impressionism together. In spare time, he usually went to visit all kinds of exhibitions and museums so as to learn from the master's artworks. He continuously explored the impressionist color and applied it into his own creation, which could be found in Venus in Dream created from 1920 to 1921, Bath created in 1924 and Moonlit Night created in 1935. This paper will analyze and discuss the relationship between Xu Beihong and impressionism as well as his artworks that were related with impressionism and were created by him before or after he studied abroad so as to explore how the popularity of impressionism painting from the latter part of the 19th century to the beginning of the 20th century affect $\mathrm{Xu}$ Beihong, an artist who can adsorb the advantages of various schools.

\section{The overview of Xu Beihong's attitude toward impressionism}

Impressionism firstly appeared in France in the 1860s and became popular in the 1970s and 1980s. At that time, some avant-garde French artists were tired of neoclassicism art. Thus, some new painting schools were created and they had a profound influence on future painting. Among these new schools, impressionism was the most impressive one. From the later period of the $19^{\text {th }}$ century to the beginning of the $20^{\text {th }}$ century, a large number of impressionist masters appeared in France, among whom, the representatives were Monet, Manet, Pissarro, Sisley and so on. Xu Beihong went to France in the first half of the $20^{\text {th }}$ century (the year 1919) and before going to France, his works were mainly calligraphy and Chinese paintings. When studying in France, he obtained certain understanding of Western paintings and started to create oil painting. Under the influence of the overall France art environment, the oil painting created by $\mathrm{Xu}$ Beihong generally showed the classicism. However, his artworks were not only affected by the France classicism. Instead, he learned the color and light application method of impressionism and applied it in Venus in Dream created from 1920 to 1921, Bath created in 1924 and some other works. He also created many outstanding oil paintings after he returned back to China in 1927. For instance, it could be found that the color and light treatment in his artwork Moonlit Night (created in 1935) adopted the impressionism method.

In the year 2004, China Art Gallery organized "Exhibition of Excellent French Impressionism Paintings" during the French Culture Year period. Feng Fasi, a student of Xu Beihong, recalled that: At that time, $\mathrm{Mr}$ Xu Beihong thought that impressionism was an expression method that were developed based on traditional and classical art and it found a new way to create new level of color expression. He did not agree that the artwork created by traditional and classic oil painting masters did not have color. For example, the artworks created by Titian, Tintorentto, Bens and Rembrandt all showed rich colors. It could be seen that $\mathrm{Xu}$ Beihong greatly affirmed the expressiveness of impressionism color application. In addition, Xu Beihong himself also conducted some study on impressionism skills. $\mathrm{Xu}$ Beihong highly appraised the artworks created by Monet, the leader of French impressionism and he summarized Monet's artwork style as "magnificent and wonderful changing". Just like traditional classical portraits, the early 
artworks of Monet showed clear light source. However, by making use of the change of light and shadow, he deliberately weakened the part that was highlighted in traditional painting and emphasized the creation of overall atmosphere, which had great innovative and revolutionary significance. The similar treatment was also used in $\mathrm{Xu}$ Beihong's artworks. For instance, Moonlit Night weakened people's importance in the painting but emphasized the change of light and the creation of overall environment atmosphere.

\section{The impressionism oil painting practice conducted by $\mathrm{Xu}$ Beihong during his stay in France}

\subsection{The influence of French teachers on $\mathrm{Xu}$ Beihong's painting ideas}

Although Xu Beihong studied in France for less than 5 years, this experience created an important turning point for his painting art. After returning back to China, he continued to use the learned painting methods. Compared with the paintings created by his tutors, Xu Beihong's paintings completely adopted the shaping relationship, color relationship and humanistic spirit taught by the tutors. In addition, Xu Beihong used more direct painting method. He directly added the painting with nontransparent color, which made the color more vivid. Different with his tutors' painting methods, he adsorbed more painting skills of realism and impressionism painting. François Flameng was $\mathrm{Xu}$ Beihong's teacher and although most of his artworks were classicism paintings, his color painting was more direct and his color hue was clearer when compared with old classicism paintings. Thus, he was very clear about the color working principle of impressionism painting. The artworks created by Pascal Dagnan-Bouveret adopted the traditional dying method but the painting themes were the realism painting themes that were common in daily life. In addition, the paintings created by Bernal completely adopted the impressionism color painting method. What's more, the paintings created by Fernand Cormon also adopted bright color. All these elements decided that Xu Beihong could get chance to learn the direct painting method adopted by realism painting and the color working principle used by impressionism painting. Besides, as he always visited uropean art galleries and museums, he had obtained a comprehensive and direct understanding of realism painting and impressionism painting. All these were the objective factors that affected Xu Beihong's art orientation.

\subsection{Xu Beihong and his impressionism painting works}

$\mathrm{Xu}$ Beihong finished Venus in dream (figure 1) in Paris, France from 1920 to 1921 and the painting was misty and beautiful. In the painting, a naked lady with graceful posture was bathing in the sun and was lying comfortably. Two sneaky orcs was peeping at the lady from the behind. This painting had strong sense of light. The bright part adopted the warm yellow color with high brightness and the dark part used cold purple color. In addition, the reflection of the green grass was also displayed $n$ the painting. The lady's face showed red color which formed a obvious contrast with the green grass. The background of the painting adopted cold gray color and the environment adopted cold green and other colors. These color application methods showed $\mathrm{Xu}$ Beihong's exploration and attempt of impressionism painting method. In order to effectively use purple color in human body painting and to effectively display human body skin, he went to Louvre to copy the artworks of Prud'hon so as to study, explore and seek for his color expression method and to improve his own color expression.

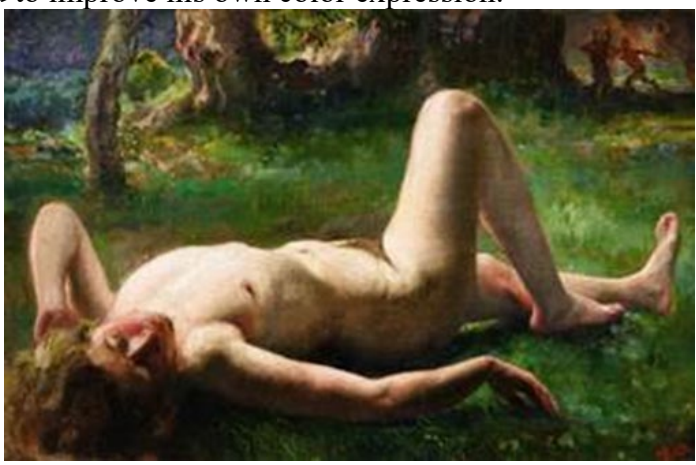

Figure 1: Venus in dream (1920-1921)

The Bath (figure 2) created in 1924 also adopted the color and light treatment method of impressionism. The painting showed the female body illuminated by warm yellow sunlight, which was complemented with the background of the purple and gray lake. The painting color was hazy and virtual, and the color of the dark part of the painted character adopted cold purple color but not the brown or dark color that used to be adopted by classic painting. The color of the dark part changed in many different ways. Especially, the dark part of human body against the light did not use single color and the color changed subtly. The color was greatly affected by the environment in the painting. In addition, instead of simply shaping the object volume by the light and shadow like traditional western oil paintings, this painting emphasized to shape the object with different colors. Besides, in Xu Beihong's painting, he did not use the traditional western oil painting method of firstly overlaying the layers together and then adding transparent colors. Instead, he directly used the nontransparent color in the painting and this method of painting the objects directly was learned from impressionism. 


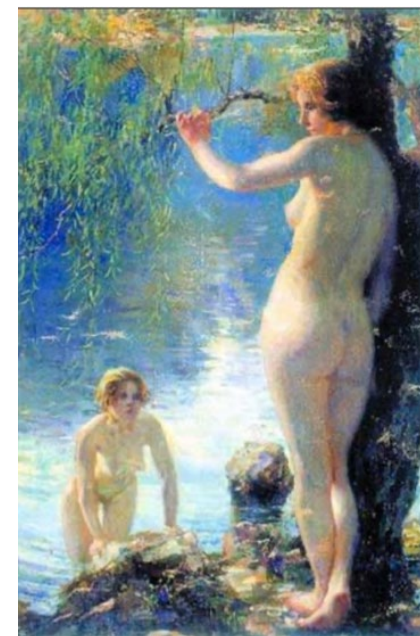

Figure 2: Bath created by Xu Beihong in 1924

In his painting Moonlit Night (figure 3) created in 1935, the moonlight was dim and was reflected in the water waves. It created a mysterious atmosphere which was the unique color expression method of impressionism. The color complementation of red and green, orange and blue as well as the capturing of light could be found in the painting. Feng Fasi commented "The color of the oiling paintings created by $\mathrm{Xu}$ Beihong was rich, splendid and brilliant. The color tone was vigorous, simple and powerful. The great charm was hidden in deep color and forceful beauty could be found in vigorous painting. His color application expressed the elegance, deposition, simplicity and richness of classical art and displayed the brightness, brilliance, liveliness and grace of impressionism art. He absorbed the best traditions of western European oil painting arts, took the advantages of various schools and combined them together. He not only reached the world-class high oil painting level but also exceeded it."

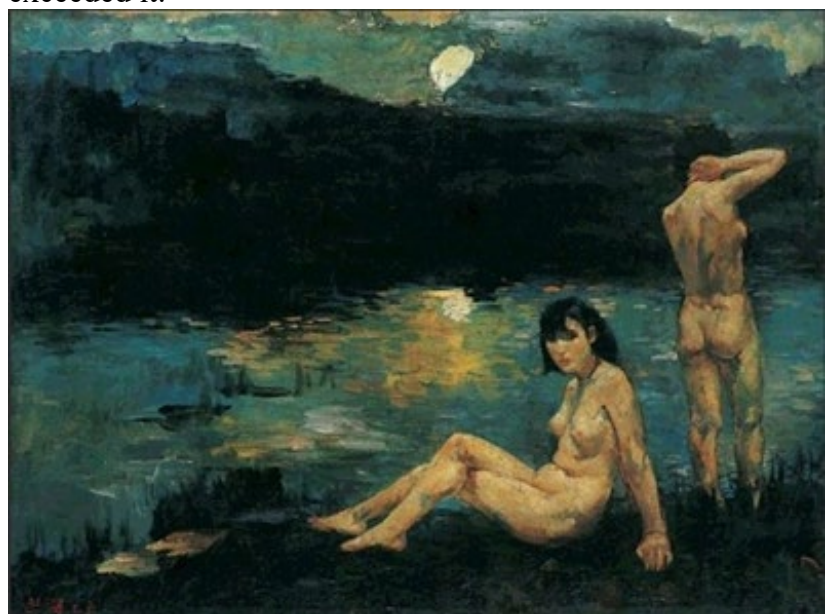

Figure 3: Moonlit Night created by Xu Beihong in 1935

At that time, the academic painting took traditional painting as the main teaching content. However, the modernism painting already appeared in the western world, which inevitably would bring some influence on National
Academy of Fine Arts of Paris and Xu Beihong. Although he mainly studied the shaping, color application and composition factors of western traditional painting, he also learned the painting method, color application, material application and skills of impressionism art. His paintings showed the combination of French naturalism and impressionism. From the paintings of Venus in Dream, Bath, Moonlit Night and other artworks, it could be seen that $\mathrm{Xu}$ Beihong adopted the color and light changing method of impressionism art to paint the female body. His paintings had strong warm and cold contrast and showed rich color changing. They no longer emphasized the sketch relations as well as light and shade comparison adopted by classical painting.

\section{The impressionism development and application conducted by Xu Beihong after he returned back to China}

\subsection{Oil paintings created by $X u$ Beihong in later period}

After returning back to China in 1927, Xu Beihong created Tian Heng and His Five Hundred Followers (figure 4), Xi Wo Hou and many other oil paintings of important historical themes. His his paintings, he expressed his best wishes to his motherland, a country that was suffering from internal and external troubles and turbulence at that time. Although most of these paintings were realistic oil paintings, the color application of these paintings showed the impressionism painting method on some degree. Although the color of the dark part of these paintings was not as transparent as that of the dark part of the lady painted in Bath, the changing of purple gray, green gray and yellow gray was adopted and these colors were corresponding with the painted surrounding environment. It could be seen that in Tian Heng Wu Zhuang Shi, the cloud in the sky at the right upper corner was similar with the cloud in Monet's oil paintings. The painted cloud showed rich bright and dark changing as well as the subtle color changing. The small parts in the painting were connected smoothly. In addition, it could be seen that the color in the dark part of the painted horse was changing vividly. Especially, the purple gray color and green gray color were crisscrossed, which enlarged the space but closely connected with the whole environment. The soil particles were not painted with single red or brown color. Instead, they were painted with many different colors which could highlight the texture and perfect the whole picture. When viewing from the distance, the painting was realistic. And when viewing from the close place, it could be found that the bold strokes were crisscrossed in the painting and the impressionism painting methods were used smoothly, which showed the real feelings of the painter. Therefore, it could be found that $\mathrm{Xu}$ Beihong maintained the realism painting method in his shaping and picture composition aspects, but his color application, paint moves and emotional expression were closer to that of impressionism. 


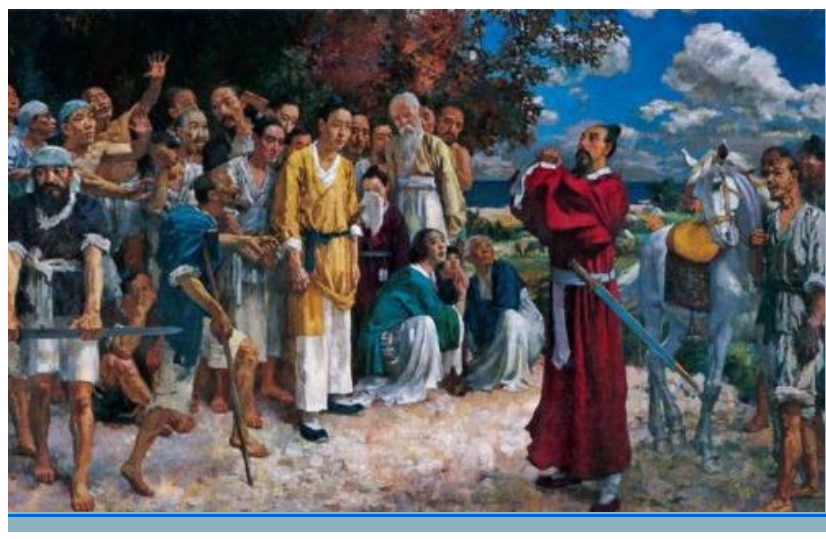

Figure 4: Tian Heng and His Five Hundred Followers created by Xu Beihong in 1930

\subsection{Xu Beihong's teaching ideas}

$\mathrm{Xu}$ Beihong returned back to China at the age of 32 (1927) after he had obtained certain academic success in France and then he started to devote himself to Chinese art education. As the first president of China Arts Association and Central Academy of Fine Art, he introduced the teaching system of western traditional painting into China for the first time. In addition, the earliest oil painting teaching of Central Academy of Fine Art, including the basic sketch teaching system and western traditional oil painting system, was also leaded by $\mathrm{Xu}$ Beihong. $\mathrm{Xu}$ Beihong adopted the direct painting method and introduced the direct painting method developed from Courbet to impressionism into Central Academy of Fine Art. In the oil paintings created by $\mathrm{Xu}$ Beihong, it could be found easily that he used nontransparent color and the thick painting methods and he did not completely introduce western traditional painting skills into China. Although $\mathrm{Xu}$ Beihong tended to use realism painting method, he advocated to learn from the nature during his teaching process. Meanwhile, impressionism painters also advocated to go out the classroom boldly, create artworks in the nature, maintain vividness in outdoor painting and directly capture the light and color.

$\mathrm{Xu}$ Beihong had two favorite students, Lv Sibai and $\mathrm{Wu}$ Zuoren. These two people were widely recognized as the capable assistants of $\mathrm{Xu}$ Beihong during the university period. Same as Xu Beihong, their beloved teacher, these two people were also outstanding artists and were also engaged in art education artwork. Under the recommendation of $\mathrm{Xu}$ Beihong, $\mathrm{Lv}$ Sibai went to study in Lyon National Academy of Fine Arts in 1928. Most of oil paintings created by him during the oversea study period did not show much ancient painting style of academic painting or the boldness style of modernism painting. He rapidly turned to the painting style of Cezanne, but later under the advice of Xu Beihong, he started to study the impressionism painters again. Therefore, it could be seen that Xu Beihong also referred to and applied the impressionism painting methods in his teaching process after he returned back to
China.

\section{Conclusion}

As a great artist and art educator of the $20^{\text {th }}$ century, $\mathrm{Xu}$ Beihong had created many excellent artworks and theories. His European study experience from 1919 to 1927 had brought indelible influence on his whole painting process, widened his vision and helped him to find the creation direction that was suitable for himself. Impressionism popularized in Europe in the first half of the $20^{\text {th }}$ century and greatly inspired him. Xu Beihong continuously explored and found his own way of painting and it was a fortune that finally he found it. The impressionism masters led by Monet greatly drove the painting development from the end of the $19^{\text {th }}$ century to the beginning of the $20^{\text {th }}$ century. They constantly promoted the art reform process of Europe and imperceptibly affected the ideas of $\mathrm{Xu}$ Beihong and other Chinese students studying abroad, which made the impressionism ideas be introduced into Chinese art in a faster pace. What Xu Beihong had left us was not only his achievements obtained during art exploration process, but also his constant art pursuit spirit and his great love for the nation.

\section{References}

[1] Liu Xiaohui, The analysis of art works created by Monet, an impressionism painter[J]. Mass Literature and Art, 2020(01): 41-42.

[2] Feng Fasi. Discussion on impressionism and contemporary Chinese oil paintings.

[3] Xu Beihong and impressionism oil painting[J]. Fine Arts, 2005(04):54-55.

[4] Yuan Xueying. The analysis of impressionism painting philosophy in Monet's paintings[J]. Art Education Research, 2018(09):14-15.

[5] Zhang Yongliang. The connection and difference between the oil paintings created by Xu Beihong and his French tutors[J]. Mass Literature and Art, 2016(05):6667.

[6] Feng Fasi. Appreciation and research of Xu Beihong's oil painting, Collection of $\mathrm{Xu}$ Beihong's oil painting, People's Fine Arts Publishing House, the edition of February, 1988.

[7] Chen Shiyi. The study on art education ideas of $\mathrm{Wu}$ Zuoren and Lv Sibai[D]. Nanjing University, 2015.

[8] Guan Hongshi. Lu Sibai in the context of Chinese art education of the 20th century[D]. Nanjing Normal University, 2005. 